\title{
Microrrelato hipermedial: hibridismo semiótico en la obra de Patricia Esteban Erlés*
}

Recibido: 26/07/2019 | Revisado: 03/03/2020 | Aceptado: 17/03/2020

DOI: 10.17230/co-herencia.17.33.4

\author{
Ana Calvo Revilla** \\ crevilla.ihum@ceu.es
}

\begin{abstract}
Resumen Con el giro del pensamiento contemporáneo hacia la cultura textovisual y multimedia, los géneros literarios, también el microrrelato, se expanden más allá de lo escrito en unas creaciones simbióticas en las que texto e imagen pueden ser contemplados de un solo golpe de vista en una unidad perceptiva. Partiendo de las estrategias narrativas que confluyen en ambos lenguajes y de la formulación conceptual de microrrelato hipermedial, se analiza la interacción de los componentes verbales y visuales (en concreto, fotográficos) en los microrrelatos que Patricia Esteban Erlés ha publicado en Facebook. El universo imaginario fantástico de estas miniaturas narrativas se reviste en la red de una gran densidad semiótica, que multiplica las redes de significación narrativa. En ese orden de ideas, se estudia la interacción que entablan los imaginarios de Patricia Esteban Erlés y Diane Arbus en torno a lo monstruoso y siniestro.
\end{abstract}

\section{Palabras clave:}

Microrrelato hipermedial, intermedialidad, narrativa visual, hibridez semiótica, fotografía, Patricia Esteban Erlés, Diane Arbus.

\section{Hypermedia Flash Fiction: Semiotic Hybridity in the Work of Patricia Esteban Erlés}

\footnotetext{
Abstract With the twist in contemporary thinking toward the text-visual and multimedia culture, the literary genres, as well as flash fiction, go beyond what is written in some symbiotic creations in which text and image can be contemplated all at once in a perceptive unit. Beginning with the narrative strategies that come together in both languages and with the conceptual formulation of hypermedia flash fiction, the interaction of the verbal and visual components is analyzed (in particular, the photographic one) in the flash fiction stories that Patricia Esteban Erlés has published in Facebook. The fantastic imaginary universe of these mini-narratives is covered with the net of the large semiotic density, which multiplies the networks of narrative significance. In this order of ideas, the interaction between the imaginaries of Patricia Esteban Erlés
}

\footnotetext{
* Este trabajo se encuadra dentro del Proyecto de Investigación I+D+I "MiRed (Microrrelato hipermedial español e hispanoamericano, 2000-2020). Elaboración de un repositorio semántico y otros desafíos en la red" (RTI2018-094725-BIO0), financiado por el Ministerio de Ciencia e Innovación, la Agencia Estatal de Investigación y el Fondo Europeo de Desarrollo (FEDER).

${ }^{* *}$ Profesora Titular de Teoría de la Literatura y Literatura Comparada, Departamento de Humanidades. Facultad de Humanidades y Ciencias de la Comunicación, Universidad CEU San Pablo, España. ORCID: 0000-00020286-5767
} 
and Diane Arbus regarding the grotesque and the sinister is studied.

\section{Keywords:}

Hypermedia flash fiction, intermediality, visual narrative, semiotic hybridity, photography, Patricia Esteban Erlés, Diane Arbus.

\section{La reflexión teórica sobre las relaciones entre las artes verbales y visuales. Estado de la cuestión}

El estudio de las relaciones entre distintas manifestaciones artísticas ha ocupado desde la Antigüedad una posición central en las disciplinas humanísticas (la filosofía, la estética, la semiótica y los estudios culturales). Si acudimos a la sentencia "La pintura sería muda y la poesía una imagen que habla", que Plutarco le atribuye a Simónides de Ceos, o a la formulación horaciana ut pictura poesis, se comprenden bien la utilización que la creación literaria hace de la imagen, los nexos que entablan las artes verbales y visuales en los procesos de ekphrasis (conversión textual de una imagen) y de hipotiposis (texto convertido en imagen), o el auge de la emblemática a partir de la publicación del Emblematum Liber (1531) de Andrea Alciato. Posteriormente, teniendo en cuenta la especificidad del sistema de signos de cada código artístico, en Laooconte o sobre los límites entre la pintura y la literatura G. E. Lessing (1776) estudió las conexiones temáticas existentes entre estas artes. Sin embargo, no fue hasta el siglo XIX cuando la demanda social de un arte cuyo fin no fuera deleitar al público sino secundar de manera provocativa las revoluciones ideológicas implementadas (De Micheli, 2001, p. 15), los cambios de la sociedad industrializada (Bou, 2001, p. 56) y la crisis del sujeto se plasmaron en el auge de la individualidad contra la uniformidad (Lucie-Smith, 2000, pp. 17-18) y en la incursión de los escritores en el terreno pictórico-visual y a la inversa, en suma, en la aspiración de las artes a prestarse formas recíprocamente (Giraldo, 2015).

A pesar de que en la actualidad asistimos a la proliferación de los intercambios entre las artes y al desplazamiento del centro de gravedad de los estudios literarios hacia la producción cultural 
(Monegal, 2016, p. 308), los discursos teóricos y críticos han girado más sobre las correspondencias (semejanzas y diferencias) de las artes en los objetos artísticos que sobre las relaciones semióticas de los componentes verbales y visuales en un objeto artístico dado. Teniendo en cuenta el giro pictórico de la contemporaneidad postulado por Mitchell ${ }^{1}$ y que la palabra y la imagen son sistemas de representación diferentes, resulta enriquecedor atender hermenéuticamente a los cruces entre las distintas manifestaciones artísticas.

No faltan teóricos que, sin embargo, solo conciben la imagen como imagen visual, excluyen la dimensión visual de la palabra y olvidan que la imagen está en el punto de partida de toda forma de representación de la realidad. Dado que la visualidad no se agota en lo visible, pues lo visible se extiende más allá de la percepción visual y alcanza lo invisible que brota de las resonancias de los imaginarios culturales y simbólicos, ${ }^{2}$ imagen y visualidad no son sinónimos pues "las imágenes no son necesariamente visuales" y porque en los textos visuales "gran parte de lo que llamamos imagen es ajeno a lo visible, o netamente invisible" (Abril, 2012, p. 29). Por este motivo, como ha defendido Antonio Monegal, la investigación se enfrenta al desafío de "resituar la problemática imagen/texto en un espacio que desestabiliza la homogeneidad conceptual" (2016, p. 310) y que nos conduce al espacio fronterizo de la différance derridiana (1968) del límite que remite a la superación de las oposiciones trazadas entre palabra e imagen (Sarabia, 2003, p. 29), al reconocimiento de la alteridad, del funcionamiento de los sistemas mixtos (de la visualidad en la textualidad y de la verbalidad en la imagen) y de las analogías entre literatura y artes plásticas como expresiones artísticas y sistemas de producción cultural que están en constante interacción (Monegal, 2000, p. 14).

1 "The realization that spectatorship (the look, the gaze, the glance, the practices of observation, surveillance and visual pleasure) may be as deep a problem as various forms of reading (decipherment, decoding, interpretation, etc.) and that 'visual experience' or 'visual literacy' may not be fully explicable on the model of textuality" (Mitchell, 1994, p. 16).

2 Sobre estos aspectos son interesantes las reflexiones de Merleau-Ponty (1970) y Walker y Chaplin (2002, pp. 41-42). 
En el ámbito de los estudios comparatistas han sido numerosos los investigadores que han abordado la cuestión de la "iluminación recíproca de las artes" ("Wechselseitige Erhellungder Künste") de que habló Oskar Walzel en Berlín en 1917, aludiendo a la confluencia de diversas disciplinas (Estética, Teoría del Arte, Semiología, Poética, Teoría de la comunicación), ${ }^{3}$ y analizando las correlaciones intersemióticas, las transposiciones existentes y la pluralidad de factores que intervienen en la experiencia estética (Albaladejo, 2016, p. 53):

Desde el punto de vista de sus singularidades pragmáticas, los fenómenos estéticos correspondientes a las diferentes artes -aquí he analizado sólo los que se refieren a la plástica y la literatura- presentan similaridades reforzadas que abundan en los testimonios de universalidad simbólicoantropológica de sus fundamentos entre la literatura y el resto de las artes. Es decir, la modificación artística que estiliza y adapta a la naturaleza peculiar del efecto estético las estructuras pragmático-comunicativas, que son propias de la percepción visual y de la simbolización verbal, intensifica el rendimiento común de los rasgos de semejanza peculiares en cada uno de los sistemas estándar pragmático-comunicativos (García Berrio, 1994, p. 633).

Por lo que respecta a la relación entre literatura y fotografía, una vez superadas la distinción que Charles Baudelaire estableció entre la poesía y la fotografía y la crítica que hizo de esta por considerar que empobrecía el genio artístico con la reproducción mimética de la realidad, asistimos a un cambio de paradigma estético de convergencia interartístico. Hasta finales del siglo XIX y comienzos del XX la aceptación de la superioridad de la creación literaria y la iconofobia de algunos escritores e intelectuales provocaron el descrédito y la invisibilidad de la fotografía (Ortel, 2002); con el cambio de siglo, las reflexiones de fotógrafos como Paul Edwards o Alfred Stieglitz le otorgaron relevancia en el panorama artístico y a partir de la década de los ochenta los teóricos empezaron a interesarse por la cultura visual y por las interacciones entre fotografía y literatura; subrayaron la visualidad de la escritura y de la lectura (Gandelman, 1991; Louvel, 2002) y afirmaron las convergencias entre ambos sistemas de significación tanto en el proceso creativo -"el acto de pensar exige

3 Cabe mencionar, entre otros, a Brunel y Chevrel (1989, pp. 245-261), Chevrel (2009, pp. 19-20), Guillén (2005, pp. 124-132), Pageaux (1994, pp. 149-166), Villanueva (1994, pp. 106-107), Weisstein (1975, pp. 297-316) y Wellek y Warren (1979, pp. 149-161). 
imágenes y las imágenes contienen pensamiento" (Arnheim, 1998, p. 267)-, como en el hermenéutico (Wagner, 1996). Son varios los factores que están implicados en la intersección de estos sistemas de representación (imagen y palabra), como la dimensión visual de la literatura que se deriva tanto de los aspectos gráficos del texto como de la capacidad de suscitar imaginarios durante el proceso de lectura; o la importancia del silencio como "palabra-imagen" (Noguerol, 2008) en algunos géneros literarios, como la poesía o el microrrelato, en el que centramos nuestra atención.

\section{Microrrelato e hibridación semiótica dentro del nuevo paradigma estético digital}

El giro pictórico-visual y multimedia del pensamiento contemporáneo no solo ha transformado los modelos hegemónicos de representación y de percepción de la realidad, sino que también ha provocado la aparición de nuevos códigos artísticos (Calvo, 2019a, p. 149). La discontinuidad y la fragmentación discursiva, la configuración de mundos etéreos y la interactividad en la esfera de la creación (Holtzman, 1994) han suscitado la multiplicación de los lenguajes "en un nivel de simbiosis e hibridación inimaginable hace veinte años" (Carrión, 2011, p. 46) y una estética más visual que textual. Los géneros literarios se expanden más allá de lo escrito en unas creaciones simbióticas que están presididas por una lingüística de la imagen y por una iconología del texto, donde texto e imagen pueden ser contemplados en una unidad perceptiva. Y, como veremos, no es ajeno a esta interacción el microrrelato.

Hasta el momento el cuarto género literario narrativo (AndresSuárez, 2012) ha sido estudiado desde distintas perspectivas; se han definido su estatuto genérico (Calvo, 2012), los mecanismos narrativos (Roas, 2010; Ródenas de Moya, 2008) y los rasgos discursivos (narratividad, hiperbrevedad, intensidad expresiva, fragmentariedad e hibridez genérica) y pragmáticos que lo configuran (Navarro, 2014); se ha subrayado su configuración posmoderna (Noguerol, 2010) y se ha analizado su relación con otras formas de minificción, como microformas fílmicas o publicitarias (Arias, Calvo y Hernández, 2009); y se han explorado los cauces digitales de difusión del género, 
como la blogosfera (Arias, 2018; Calvo, 2016; Carrillo, 2018), las revistas digitales (Bustamante, 2016, 2017; Calvo, 2018a) y las redes sociales (Calvo, 2018b; Hernández, 2018; Navarro, 2014).

Estos estudios han puesto de manifiesto que la flexibilidad, la viralidad y la capacidad hipermedia y multimedia de los espacios de publicación actúan como dinamizadores de estas microformas literarias narrativas que se consolidan en la red. El microrrelato se adapta a la lectura integral que requiere la pantalla digital, a la configuración de un post en la blogosfera o al formato de 140 caracteres de Twitter, espacios donde integra elementos multimedia y muestra la mutación visual del mundo expandido en el que nos encontramos inmersos (Escandell, 2018). Son numerosos los escritores de microrrelato que están integrados en una cultura en red, que desplaza el foco de atención de la palabra (logos) a la imagen (imago) y asiste al descentramiento del logocentrismo, al entrecruzamiento y visualización de imágenes y palabras y que, imbuidos de la tradición literaria, sin renunciar al texto impreso y gracias a los dispositivos tecnológicos, no renuncian a las posibilidades creativas que estos suscitan.

Como hemos puesto de relieve en anteriores estudios, con el término de microrrelato hipermedial aludimos al protagonismo adquirido por las redes en los procesos de creación, difusión y recepción del género y a las interacciones que entabla el microrrelato con otras manifestaciones artísticas debido a diversos fenómenos, como la intermedialidad (Rajewski 2005), ${ }^{4}$ multimedialidad e hipermedialidad (Calvo, 2017; 2019a; 2019b). En la esfera digital estos escritores integran en sus miniaturas narrativas imágenes (fotografía, ilustración, gráfico), vídeos y elementos auditivos (música o sonido) o animaciones que, extraídos de su contexto original, permiten la creación de un nuevo material textual-literario. En la representación ficcional estas miniaturas narrativas híbridas muestran "imaginarios icónicos" de gran densidad semiótica, lo que multiplica las redes de

4 A partir de la formulación conceptual del término intermedia por parte de Higgins en The Something Else Newsletter (1966) y desde que Kristeva subrayó la significación textual (1969, pp. 143-173), se ha aludido a distintas formas de codificar la experiencia humana en los nuevos contextos comunicativos y a la dificultad de trazar límites en la creación artística debido al entrecruzamiento de medios, materiales técnicos, códigos sígnicos y estéticos. 
significación de narratividad. En consecuencia, su análisis lingüístico ha de prolongarse al imaginario que se extiende más allá del material verbal inmanente, procedente de la dimensión semántica de los símbolos y de la configuración de la espacialidad ficcional de los componentes verbales y visuales.

Como ha subrayado Magdalena Perkowska, fotografía y literatura "han dejado de ser formas antagónicas" (2013, p. 17). Texto literario e imagen comparten la estructura físico-material de sus soportes respectivos y de los elementos expresivos y presignificativos; mientras el cromatismo o el encuadre de la imagen son relevantes en la significación visual, los elementos fono-acústicos (rimas, aliteraciones) lo son en la significación verbal; asimismo, la imagen comparte varios rasgos con las variedades proteicas de la brevedad, como la ambigüedad, la condensación, la unidad de percepción, el poder simbólico y epifánico, la sugerencia, la significación de la elipsis, etcétera, de ahí que haya sido uno de los principios constitutivos de la minificción (Noguerol, 2008, p. 185).

Gracias a las semejanzas estructurales derivadas de la condición textual de las dos clases de obras artísticas (texto literario e imagen artística) y a la homología pragmática que regula ambos sistemas expresivos y comunicativos (García Berrio y Hernández, 1986, p. 49), la interpretación hermenéutica de los microrrelatos hipermediales, en los que interactúan estos códigos artísticos en la doble vertiente expresivo-creativa y receptiva, ha de partir de los mecanismos que operan en la interacción de los componentes visuales (fotografía, ilustración, pintura) y verbales, pues el lector ha de desentrañar las significaciones que surgen de la simbiosis semiótica. La relación interartística puede surgir de modos diversos; la imagen puede ser, como plantea Antonio Monegal, un pretexto para el texto literario, "sirviendo como fuente de una experiencia o como anclaje temático" (1996, p. 310); en este caso nos encontraríamos ante microrrelatos hipermediales, que tienen de alguna manera a la fotografía en su génesis; y también la imagen puede ser un "intertexto necesario para la lectura", que aporta elementos sin los cuales sería incompleta su interpretación (1996, p. 310); en este caso estaríamos ante microrrelatos simbióticos, donde imagen y texto guardan una relación de complementariedad y mantienen una relación significativa; 
también puede haber en el ciberespacio microrrelatos que están acompañados de una imagen, con la que no mantienen ninguna interacción, por ser un relleno. Si detenemos nuestra atención en los dos primeros tipos, apreciaremos una narrativa dinámica y dialógica procedente del hibridismo semiótico, como veremos a continuación.

\section{Microrrelato hipermedial: el diálogo de Patricia Esteban Erlés con Diane Arbus}

Literatura y fotografía aparecen estrechamente imbricadas en las miniaturas narrativas hipermediales de Patricia Esteban Erlés, escritora prolífica que ha cultivado distintos géneros literarios. ${ }^{5} \mathrm{Su}$ producción literaria en el ámbito del microrrelato constituye un claro ejemplo de la proliferación del género en el ciberespacio. La simbiosis textovisual impregna su proceso creativo en la red, donde muestra su capacidad para contar historias a través de la interacción de los componentes verbales y visuales, especialmente fotográficos, motivo por el cual analizamos este aspecto.

Partiendo de que una de las fuentes nutricias del pensamiento y de la obra de arte es el asombro frente a la incomprensión, la belleza o la complejidad, la obra fotográfica de Diane Arbus se presenta a los ojos de la escritora zaragozana como una obra abierta que suscita un ejercicio de reescritura dialógico. Como figura en la siguiente anotación de Esteban Erlés, inicialmente la contemplación de la fotografía la impele a hacer un ejercicio de reflexión descriptiva, que contiene en germen varios imaginarios narrativos:

5 Patricia Esteban Erlés ha obtenido el Premio de Narración Breve de la Universidad de Zaragoza en 2007 con Manderley en venta (2008b) y el XXII Premio de Narrativa Santa Isabel de Aragón, Reina de Portugal, con Abierto para fantoches (2008a); posteriormente escribió Azul ruso (2010) -con él fue finalista en el Premio Setenil-, publicó su primer libro de microrrelatos Casa de muñecas (2012), la novela Las madres negras (2018c) y recientemente Fondo de armario (2019), donde reúne las columnas publicadas en Heraldo de Aragón. 


\title{
Imagen 1
}

Esta imagen de Diane Arbus...

\begin{abstract}
Esta imagen de Diane Arbus siempre me sobrecoge. Una mujer lleva un niño en brazos y camina por Central Park. Parece cargar el peso absoluto del atardecer. Parece que abandona una guerra o que acaban de abandonarla a ella con una simple nota y ese chicuillo al que podría abandonar sobre el cesped para fingir que la vida empleza justo en el momento en que nos sabemos capaces de la peor de las vilezas. Parece tal vez que no sabe que cenarán esa noche. Parece que no es feliz, que su hijo haya muerto mientras jugaba en los columpios y no se atreva a creerio y lo lleve pegado a su pecho para devolverle la vida a fuerza de desearlo mucho. Parece que es muy joven y muy vieja, alguien que quizás se pregunte a veces si ella deberia ser tan pronto la madre de alguien.
\end{abstract}

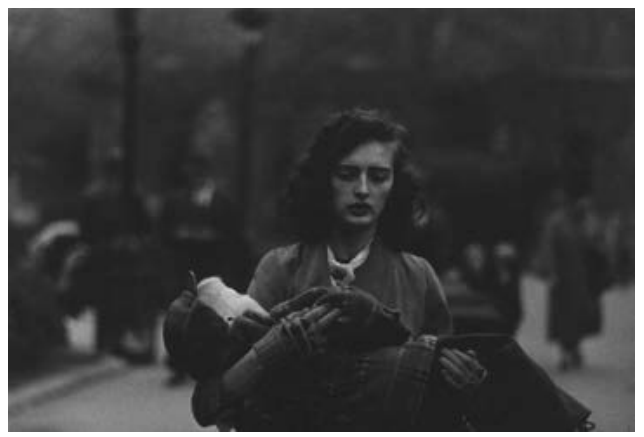

Fuente: Patricia Esteban Erlés, 31 de mayo de 2020,

Facebook [imagen adjunta], https://bit.ly/3fY8vrj

Se refiere Patricia Esteban Erlés a la fotografía "Woman Carrying a Child in Central Park, N.Y.C., 1956", que fue realizada por Arbus en un momento crucial de su trayectoria profesional, cuando abandonaba el mundo de la moda en el que había trabajado junto a su marido y comenzaba a desarrollar la carrera por cuenta propia y a interesarse por la naturaleza oculta de los seres que deambulan por la calle, llenos de incógnitas que exigían ser desentrañadas.

Sobresale el carácter narrativo de la imagen visual, donde la artista encuadra la escena que protagoniza uno de esos seres solitarios, que al margen del tumulto y del ruido que los rodea, se impregna de un alto potencial semántico introspectivo y con su sola presencia suscita preguntas al espectador. Teniendo en cuenta que, como dijo Barthes en La cámara lúcida, sea lo que sea lo que la fotografía ofrezca a la vista y la técnica empleada, "siempre es invisible: no es a ella a quien vemos" (1989, p. 34), Esteban Erlés, seducida por el punctum, que la lastima y punza $(1989$, p. 65) se convierte en spectator -siguiendo la nomenclatura barthesiana- que va más allá de la revelación química 
del objeto visual. La imagen aparentemente fría de una madre rota con el cuerpo de su hijo muerto entre los brazos es transformada por su visión intimista en una miniatura narrativa de gran fuerza visual. Lo fotografiado (spectrum) es ese algo terrible que lacera, "el retorno de lo muerto" (Barthes, 1989, p. 39) y se convierte en leitmotiv de esta miniatura narrativa; según podemos observar, viene enfatizado por la presencia recurrente del verbo "parecer" y es lo que le permite incoar varios escenarios narrativos; al captar el aire de la imagen fotográfica, "esa cosa exorbitante que hace inducir el alma bajo el cuerpo" (Barthes 1989, p. 183), brotan algunas de las posibles historias subyacentes:

La fotografía, a veces, hace aparecer lo que jamás se percibe en un rostro real (o reflejado en un espejo): un rasgo genético, el pedazo de uno mismo o de un pariente que proviene de un ascendiente [...] La fotografía ofrece un poco de verdad, con la condición de trocear el cuerpo. Pero dicha verdad no es la del individuo, que sigue siendo irreductible; es la del linaje (Barthes, 1989, p. 177).

Como vemos, partiendo de la elipsis de la composición fotográfica de esta pietà, Esteban Erlés llena los huecos y vacíos de indeterminación que plantea la narración visual y plasma con los ojos de la imaginación los mundos hipotéticos que quizá no han sido pero que podrían haber sido, como subrayó Italo Calvino. ${ }^{6}$ Es la elipsis uno de los rasgos donde convergen ambas manifestaciones artísticas, pues también en el microrrelato lo no dicho es más significativo que lo explicitado (Andres-Suárez, 2008).

El universo fotográfico de Diane Arbus y su mirada desgarrada del mundo se convierten para Esteban Erlés en un símbolo, que condensa bien la naturaleza fantástica que preside su narrativa, como vemos en esta anotación:

6 Italo Calvino en Seis propuestas para el próximo milenio afirmó que el hombre es capaz de "enfocar imágenes visuales con otros ojos que no son los que tenemos todos enfrente" y desplegar su imaginación "como repertorio de lo potencial, de lo hipotético, de lo que no es, no ha sido ni tal vez será. Pero que hubiera podido ser" (1998, p. 97). 


\section{Imagen 2}

Shirley Jackson, Silvina Ocampo, Fleur Jaeggy...
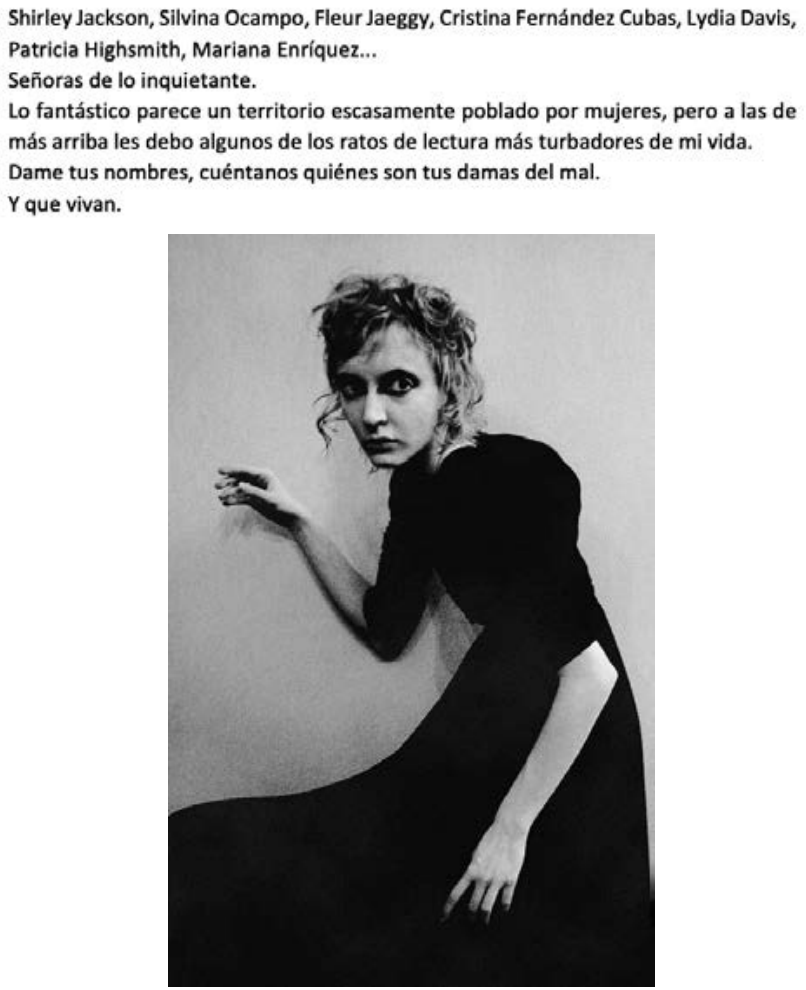

Fuente: Patricia Esteban Erlés, 8 de agosto de 2017, Facebook [fotografía de Diane Arbus], fecha de acceso: 26 de abril de 2019, https://bit.ly/3gvOFnD

Comparten escritora y fotógrafa el gusto por lo excéntrico, lo inusual y lo diferente; más allá de la predilección de Arbus por cierta tipología de personajes (travestis, nudistas, gigantes, homosexuales, seres deformes o dementes, personajes circenses), la alteridad, la identidad y la diferencia son motivos recurrentes en ambas artistas. Los rostros extraños y desconocidos, que son amenazadores por su naturaleza diferente, iluminan el incómodo y desasosegante imaginario de Esteban Erlés y sostienen su empeño obstinado por mostrar la convivencia de la alteridad y de la monstruosidad con un elevado grado de conciencia de la normalidad y la temporalidad en la que le corresponde vivir; de manera semejante al modo en 
que la fotógrafa estadounidense supo retratar a través de la mirada y del movimiento el alma de los personajes, la escritora desentraña de manera intuitiva los secretos que cada uno guarda en su interior (De la Varga, 2015). Lo observamos en el siguiente microrrelato:

Imagen 3

Eran tres hermanos...

Eran tres hermanos, tenian tres tamaños distintos y la misma cara triste, como las matrioscas. Parecia que los había dibujado alguien, pensando en tres tallas diferentes de niños perdidos. La hermana mayor, el mediano, mi compañero de clase, uno más pequeño. Los tres miraban igual, como si hubieran regresado varias veces de la misma pesadilla y supieran, eso era lo peor, que iban a volver alli en cuanto anocheciera. Vestían como protagonistas de una serie de televisión antigua, como niños de otra época, pantalones de campana y camisetas apretadas, zapatillas que parecian haber sobrevivido a un accidente de tráfico. Eran los chicos más solitarios del colegio y mi compañero, el hermano mediano, parecia que iba a echarse a llorar de un momento a otro, mientras la maestra escribía una estúpida oración, Tengo muchos amigos, en la pizarra negra. Como si las peras le partieran el corazón, como si pensara que era la frase más tonta que alguien podía pronunciar o hacernos copiar. Pero nunca lloraba y aquello era lo peor de todo, esos dos ojos nublados en la cara de un chaval que salía del colegio vestido como el pequeño de Con ocho basta y volvia a la casa $\sin$ luz, ni agua, ni padres.

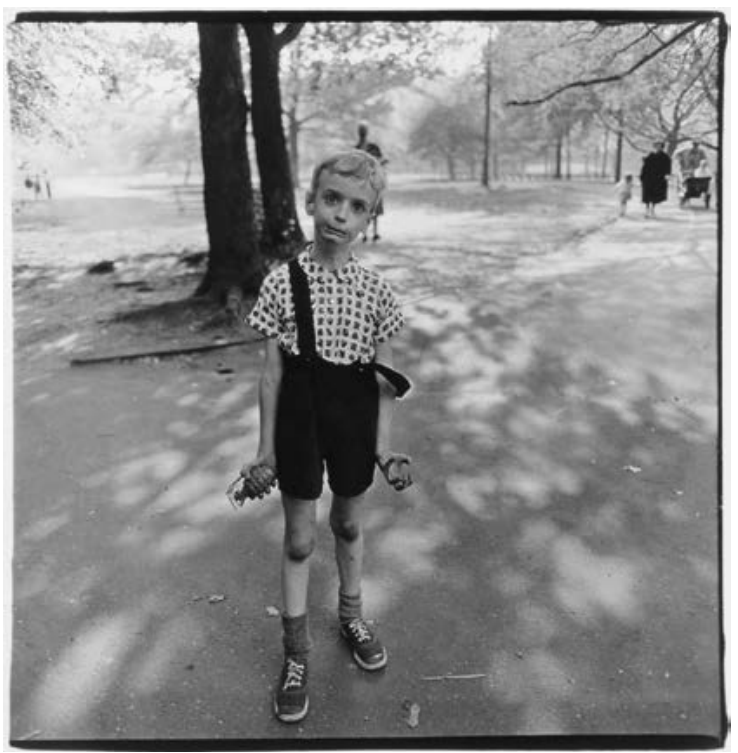

Fuente: Patricia Esteban Erlés, 26 de septiembre de 2017, Facebook [fotografía de Diane Arbus], fecha de acceso: 26 de abril de 2019, https://bit.ly/3k2HOis 
En esta ocasión se sirve de la célebre fotografía "Child with a toy hand grenade in Central Park, N.Y.C." (1962) de Diane Arbus, en la que un niño con un rictus extraño, la expresión enloquecida del rostro y una inusual granada que sostiene con su mano agarrotada y rígida, simboliza el aislamiento y la soledad. No sorprende que el referente de la escritora para esta historia de pesadilla y orfandad sea la imagen de este niño enigmático, que retiene en su mirada y en su cuerpo la tristeza y el desvalimiento y cuya vida aparece expuesta a los horrores del mundo adulto, a la carencia de afecto, a la violencia y a la guerra. Como es habitual en la narrativa breve de la escritora, la infancia dista de ser una etapa de la vida idílica, despreocupada y perfecta; los protagonistas son niños angustiados y enigmáticos, de mirada consternada y ojos nublados que vuelven a casa "sin luz, ni agua, ni padres"; son espectros asustadizos que habitan un mundo apocalíptico y fantasmal, que bien puede ser una réplica perversa del vacío y de la monstruosidad del mundo adulto. Condensa este microrrelato hipermedial la poética de la escritura, como ella refleja:

Creo que la literatura es un ejercicio, en general, de plasmación libre de todo lo que en la realidad no tiene cabida. A mí al menos la literatura me permite pensar en las zonas más sombrías, en las tinieblas del ser humano. Me gusta que exista un espacio para reflexionar sobre el cien por cien de lo que somos, sin censura ni prisas por iluminar aquello que resulta menos explicable. El ser humano es luz y sombra. La crueldad es una de las manifestaciones más elocuentes de esa oscuridad que albergamos. Es una pulsión a veces irresistible, que sabes de antemano que deja víctimas, dolor, pero la ejercemos de forma más o menos sutil en ocasiones, como si fuera más fuerte que nosotros, como si necesitásemos dejarla salir, obrar. Todos sabemos lo que está bien y lo que no. Y, sin embargo, la crueldad existe, es. Nos rodea, la leemos a diario, nos encontramos practicándola como si fuera un mandato interno el que rige nuestros actos. Creo que escribir sobre la crueldad es una manera de ejercerla sin víctimas reales (Esteban Erlés, 2018a, p. 214).

Ambas artistas sobresalen por su capacidad para despertar el miedo sin eludir lo que la vida cotidiana encierra; no se limita la escritora, como tampoco lo hizo la fotógrafa, a imitar lo acontecido sino a sobrepasar el umbral esperado. Mediante la narración de lo que resulta doloroso o perturbador, traza magistralmente las fronteras morales entre lo que se vive y lo que no es vivible humanamente. 
La célebre tesis de Susan Sontag: "Fotografiado por Diane Arbus, cualquiera es monstruoso" (1973, p. 43), bien puede ser atribuida a la escritura monstruosa, extraña e inquietante de Esteban Erlés, ante la cual "es muy difícil mantener una distancia", como dijo Lisette Model de Diane Arbus (2010, p. 24):

$\mathrm{Al}$ acostumbrarnos a lo que anteriormente no soportábamos ver ni oír, porque era demasiado chocante, doloroso o perturbador, el arte cambia la moral, ese conjunto de hábitos psíquicos y sanciones públicas que traza una borrosa frontera entre lo que es emocional y espontáneamente intolerable y lo que no lo es (Sontag, 1973, p. 51).

\section{Espejismos y distorsiones de la realidad desde otras narrativas visuales}

Palabras e imágenes operan, como vemos, dentro de un espacio de significación híbrido, que cuestiona el modo hegemónico de representar la realidad. En ocasiones, partiendo de la observación de imágenes oníricas y surrealistas, la escritora construye una historia mediante un proceso de desenmascaramiento irónico. Nos detenemos en un microrrelato, cuya trama sigue los cauces naturales a través de los cuales la incomprensión o la complejidad buscan el esclarecimiento:

\footnotetext{
Imagen 4

En esta ciudad pasa de todo...

En esta ciudad pasa de todo.

Por ejemplo, ya no reparten el verbo vivir en la puerta de algunos cines como antes. Ha volado a lo alto de un rascacielos y anida alli como un buitre soberbio. Un adolescente se suicida una y otra vez, usando la corbata estrecha de su padre porque aún le da miedo el cinturón de cuero que él deja cada noche sobre la silla. Una mujer jura ante la pila del fregadero que de hoy no pasa y va sumando un ayer tras otro al mismo rostro de cera.

Se juntan los viejos drogadictos en una calleja estrecha y lloran recordando la blancura de leche de aquel polvo que dejó de ser rentable. Se manda fusilar todas las canciones que hacen llorar a alguien.

Se espera a que deje de nevar para que los operarios puedan empezar a desenterrar en paz a todos esos muertos de invierno.

En esta ciudad pasa de todo mientras tú y yo nos olvidamos.

(Foto Twins Paper Bags de Nicolás Ferrando, a partir de las Twins de Diane Arbus).
} 


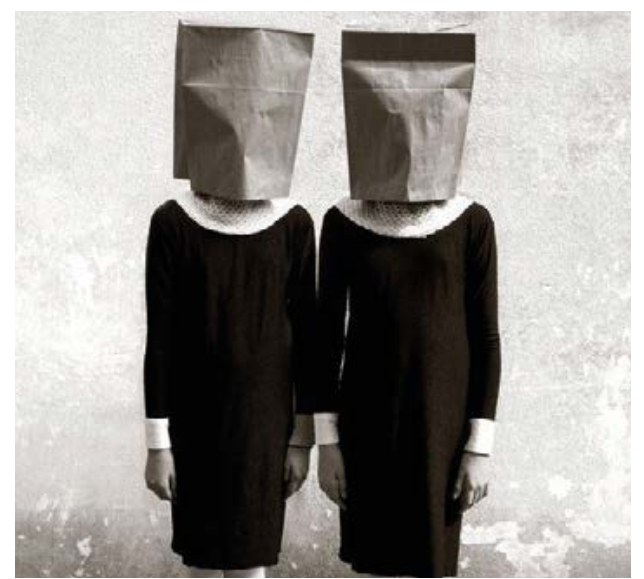

Patricia Esteban Erlés, 25 de diciembre de 2018, Facebook [fotografía de Nicolás Ferrando], fecha de acceso: 26 de abril de 2019, https://bit.ly/2PfDaEI

Como sostiene Magdalena Perkowska, la inserción de fotografías en textos ficcionales "desestabiliza las categorías de leer y ver, ficción y no ficción, tiempo y espacio, pasado y presente" (2013, p. 57). Este microrrelato hipermedial tiene un efecto disruptivo o perturbador, que deriva en gran medida de la interacción de los componentes verbales con los visuales; entabla diálogo con las emblemáticas bolsas de papel sobre la cabeza de las protagonistas del fotógrafo argentino Ferrando, para quien la imagen fotográfica nunca es un reflejo de la realidad sino una interpretación de la misma; del juego entre el texto visual y el texto verbal surge el punctum barthesiano, el dardo que brota de la imagen para impactar al lectoespectador (Mora, 2012). Microrrelato y fotografía potencian el efecto de extrañamiento, enfatizan el diálogo estético, ideológico, cultural y social, permiten la interferencia dialógica e influyen en la construcción de la representación ficcional de extrañeza de un mundo deshumanizado. Esteban Erlés sitúa la trama en un espacio urbanístico fantasmal y siniestro, $^{7}$ en el que de manera recurrente la muerte y sus espectros y los miedos cercan la vida de los habitantes; la vida de la ciudad se

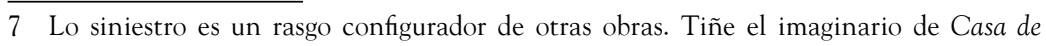
muñecas, como han puesto de relieve los estudios de Rosa María Díez Cobo (2018), Ana Calvo Revilla (2019c) y Ana Abello Verano (2019). 
tiñe del tedio de los habitantes de "La lotería" de Shirley Jackson y del horror que se instala (Esteban Erlés, 2018b), carcome la realidad y perfora el corazón humano; el sinsentido de la existencia está proverbialmente trazado: "ya no reparten el verbo vivir" porque los muertos de invierno lo acaparan y arañan todo. Microrrelato y fotografía alzan un imaginario distópico y grotesco de la realidad, una radiografía metafórica de la devastación.

Llama la atención la intertextualidad visual presente en este microrrelato hipermedial, que en su pie de foto incluye la referencia explícita a la fotografía "Identical Twins, Roselle, N. J.", que fue elaborada por Diane Arbus con la técnica de la impresión de gelatina de plata:

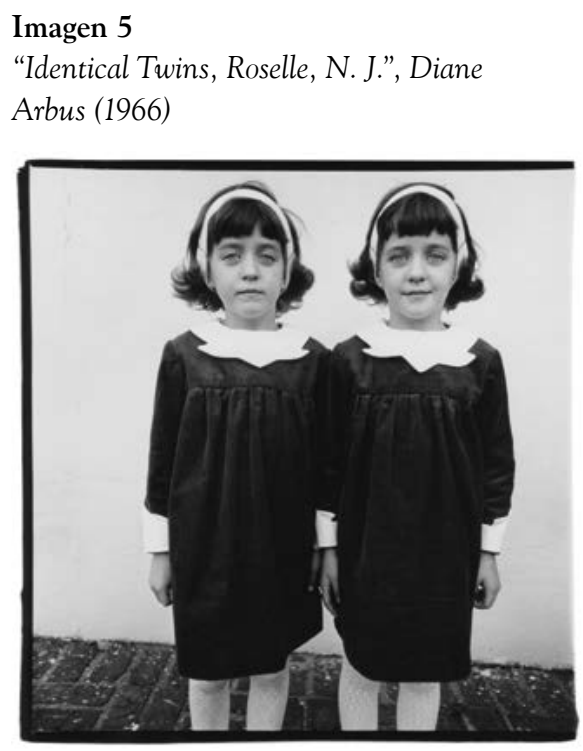

Fuente: The J. Paul Getty Museum, https://bit. ly/3k7emx1

En esta fotografía que Diane tomó con motivo de una fiesta navideña para gemelos y trillizos en Roselle, ciudad de Nueva Jersey, establece un juego conceptual sobre la identidad personal, bajo la influencia de Freaks (1932) del director Tod Browning; el ángulo frontal desde una altura algo inferior a los ojos traslada la intencionalidad que preside su producción artística: descubrir el 
otro mundo, encontrarse con la alteridad, como supo atisbar Susan Sontag: "[...] las fotografías de Arbus -con su admisión de lo horrorosoevocan una ingenuidad esquiva y siniestra a la vez, pues esta se basa en la distancia, en el privilegio, la impresión de que al espectador se invita a ver realmente lo otro" (Sontag, 1973, p. 41). El misterio que late tras la imagen de estas muchachas, que ante una pared blanca aparecen vestidas de un negro que en realidad es un verde, abre una brecha entre lo que observamos (las semejanzas y diferencias entre la sombría Cathleen y su hermana Colleeen) y lo que se nos pide ver. Comparte Esteban Erlés con Arbus la atracción por la diferencia y por lo inusual. La palabra es para ella, como fue la cámara fotográfica para la fotógrafa, un instrumento de análisis y crítica; con la interacción visual consigue expresar una fricción cognitiva y una incredulidad semejante a la que provocaban las fotografías de Arbus, un halo de misterio y de incógnita, que atrapa al lector.

En otra ocasión, sin seguir la estela de Diane Arbus, publica en la red un microrrelato junto a una fotografía de las siniestras gemelas que el ilusionista e hipnotista británico Derren Brown situó en la ciudad londinense (Charing Cross, Oxford Street, Regent's Street, Hamleys) para promocionar una actividad en el parque temático Thorpe Park:

\title{
Imagen 6
}

Te peinaré siempre que tú me lo pidas...

\begin{abstract}
Te peinaré siempre que tú me lo pidas, le decía la gemela fea a la gemela guapa, asumiendo su papel de pequeña doncella condenada a las sombras. A la gemela guapa le gustaba escuchar cerca la respiración perruna de su hermana, saberla despierta en la oscuridad las noches de tormenta en que velaba su sueño. Te prohíbo dormir, le decía, no te duermas antes que yo, y si viene el monstruo, tiene que comerte a ti primero. La gemela fea agitaba la cabeza. Obedecía y aguantaba la respiración, le anudaba el lazo del vestido, lustraba sus zapatos blancos de charol, cualquier cosa que ella le pidiera era una orden, el deseo irrevocable de un ser perfecto, de esa versión ideal de sí misma, la que estuvo a punto de ser y no fue. La gemela fea continuó peinándola cada noche, alisando cada mechón de su cabello una y cien veces ante el espejo, aunque la gemela guapa llorara bajito y le dijera que ya no, que por favor ya no. Sorda, como la lealtad de un perro que ni muerto deja de amarte.
\end{abstract}

(Imagen de las dos muñecas victorianas y gemelas que salieron a darse una vuelta por London y cogieron el metro para espanto de pasajeros y otros seres). 


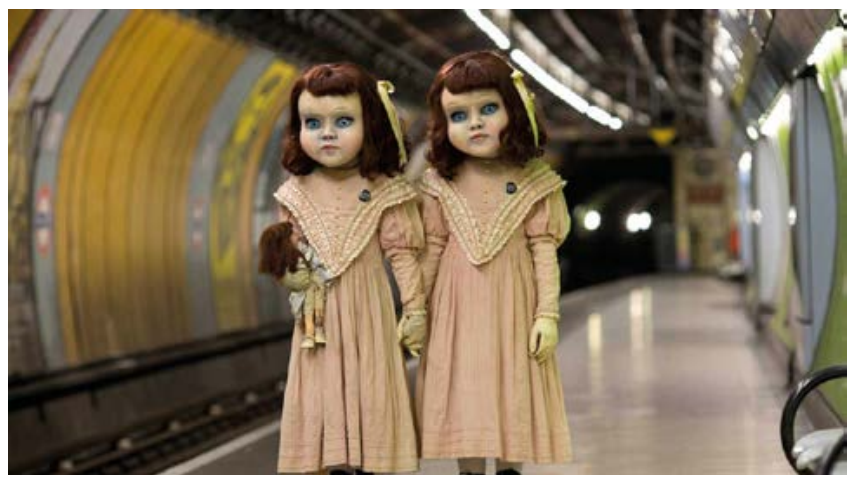

Fuente: Patricia Esteban Erlés, 18 de julio de 2019, Facebook, [imagen adjunta, s. d.], https://bit.ly/3gb8cJJ

Patricia ya había publicado este microrrelato en Facebook el 7 de octubre de 2011 con otra fotografía; y también publicó esta pieza narrativa en Casa de muñecas con el título "La gemela fea" (Esteban Erlés, 2012, p. 46). Reescribe en él una de las formas que el motivo del doppelgänger ha adoptado a lo largo de la tradición literaria, desde la doble naturaleza moral de El extraño caso del Dr. Jekyll y $\mathrm{Mr}$ Hyde hasta el doble corpóreo o escindido de la psique, que tan magistralmente dibujó Edgar Allan Poe, o E. T. A. Hoffmann en Los elixires del diablo. Tanto el desdoblamiento que aporta la imagen de la muñeca (juguete/ser humano) como la ambivalencia entre lo inanimado (su ser estático, semejante a un cadáver) y lo viviente (su actuar como ser vivo irritado y distante) y la reversibilidad o la inversión de la imagen de la infancia (inocencia/perversión) se hacen portadores de lo siniestro, que asume lo pavoroso (tó deinón) y lo ominoso (unheimlich) y se tiñen de la aterradora fascinación que ejerce el motivo del doble. Tras un juguete que no lo es y tras las apariencias de unas tiernas criaturas que no lo son, el mundo de la infancia es trastocado.

Este microrrelato hipermedial introduce al lector en un imaginario exquisito y cruel, en el que la escritora sigue la estela de Silvina Ocampo o de Mariana Manríquez. Mediante una extraña conjunción de belleza y espanto -habitual en las miniaturas narrativas que configuran el libro de microrrelatos Casa de muñecas- 
Esteban Erlés dota a las muñecas de rasgos vivientes y las impregna de su capacidad para lo siniestro. Si la imagen de las gemelas produce, como el monstruo, curiosidad, repugnancia y miedo, su comportamiento en la miniatura narrativa gira entre la locura, la frustración y el absurdo y provoca escalofríos. Las protagonistas se asemejan a las erinias, que dejan aflorar la crueldad y la perversidad, albergan lo monstruoso con maniobras sádicas y poetizan lo abyecto, enfatizando el defecto disruptivo.

En ocasiones microrrelato y fotografía como intermediarios simbólicos comparten idéntica referencialidad icónica, como vemos a continuación:

\title{
Imagen 7
}

Tu muerte era muy pequeña...

\begin{abstract}
Tu muerte era muy pequeña, cabía en una toalla nueva, que aún olía a nueva. Tu muerte apenas dejó la sombra de un pliegue en la cama de matrimonio donde te velaron, con los ojos resecos, muertos también por puro respeto, una madrugada. Se hizo de dia, la noche se marchó por esa puerta como habia venido y todos tendrian pronto otras cosas que hacer. Llegó el carpintero, tocó a la puerta tres veces, como en los cuentos, y decidieron empezar a vestirte, con la ropa más bonita de todas, como si fueras a dar un paseo. Tu muerte fue muy pequeña, casi invisible, sonaba a rezos antiguos y sollozos contenidos. Pero a tu madre se le quedó en los brazos el hueco irremplazable de tu cuerpo de muñeca, y hubo horas en el día que ya nadie supo llenar $\sin$ ti. Tu muerte se extendió por el pueblo metida en una caja que parecia el cofre del tesoro de alguien. La vieja de los ataúdes recorrió la calle principal cargando tu muerte como si fueras agua y todo el pueblo siguió el sendero que llevaba al camposanto. Alli se juntó con todas las otras muertes, que habian sido más o menos del tamaño de la tuya. Alli las ancianas temblaron y las madres jóvenes se acariciaron por instinto el vientre al sentir que la muerte grande, la que hiela la sangre y te tumba de un golpe seco, se paseaba entre las cruces y los vivos, rozándoles las trenzas con sus dedos de hueso.
\end{abstract}

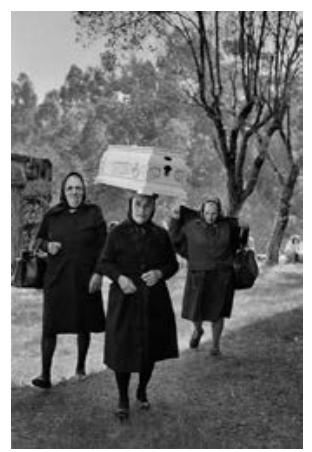

Fuente: Patricia Esteban Erlés, 7 de julio de 2019, Facebook, [imagen adjunta, s. d.], https://bit.ly/2PILFON

Nos encontramos ante un microrrelato hipermedial de tono ecfrástico con alguna característica peculiar; la escritora narra una de las posibles historias que laten tras la representación plástica fotográfica, mediante un proceso mimético doble e ilusorio; siguiendo la tesis de Michel Riffaterre estamos ante una mímesis ilusoria, pues "no da a ver más que una interpretación dictada menos por el objeto real o ficticio que por su papel dentro del contexto literario" (1994, p. 211; mi traducción). A pesar de que la imagen fotográfica alcanza un nivel de referencialidad mimética y de verosimilitud semántica elevada, en el contexto comunicativo-pragmático el sistema de representación que se deriva de la perspectiva, del cromatismo o de 
la configuración espacial de los tres cuerpos adopta un significado diferente. La fotografía actúa como pretexto y se extiende más allá de la referencialidad a la procesión de cadeleitos, que se celebra en Santa Marta de Ribarteme. La fotografía, contemplada de manera autónoma, representa a tres mujeres integrantes de un desfile procesionario de ataúdes y centra su atención en la mujer vestida de luto, que parece llevar sobre sus hombros el féretro de un miembro pequeño de la familia para solicitar con sus plegarias la intervención de la santa. El realismo fotográfico de esta costumbre que la tierra gallega heredó de alguna orden religiosa contrasta con el significado ficticio que la imagen adquiere en el microrrelato. La voz narradora penetra visualmente en la escena y la evoca a través de una interpretación. Mientras la imagen fotográfica retiene una escena costumbrista que aspira a capturar el tiempo para rehuir el paso de la muerte, junto al microrrelato apresa aún más el marco espacio-temporal, no logra trascender la muerte ni evita salvar el rostro del hijo de la abrasión del tiempo. El lectoespectador (Mora, 2012) no se detiene ya tanto en la imagen, sino en el sujeto narrador que capta con ternura poética y cruel los intentos de la madre por sobrevenir a la muerte y al sinsentido, que tan bien refleja el hueco irremplazable del cuerpo.

La metáfora de la muerte se confirma, como veremos también a continuación, como un dispositivo retórico esencial en los microrrelatos hipermediales de Esteban Erlés, pues contribuye a la creación de la narrativa verbal y visual; al trascender los límites lingüístico-verbales, el motor metafórico, como lo denomina Tomás Albaladejo, "actúa gracias a la capacidad humana de determinar la semejanza por semas comunes entre los elementos que intervienen en dicho proceso como elemento presente y como elemento ausente" (2016, p. 55): 


\section{Imagen 8}

Me acuerdo de cuando confundimos la muerte...

Me acuerdo de cuando confundimos la muerte con un columpio.

Una compañera que estudió en el Pedro de Luna me contó que la ventana de su clase daba a una explanada a la que los yonquis iban a pincharse. En plena clase de Matemáticas los veian llegar con sus jeringuillas. Un lunes, a las once de la mañana, entre infinitos y cosenos, aquellas dosis de sordidez que nadie se molestaba en ocultar. La profesora seguia dando clase. Los drogadictos iban y venian, como muertos vivientes.

Yo que fui al Blecua recorria cada dia un camino para llegar. Lo llamábamos el atajo. Una mañana, entre los pinos, había un ahorcado. cHabéis visto al colgao?, decian entre risas los que iban por delante. Yo imaginaba a uno de aquellos yonquis destrozados que deambulaban por el barrio, pero no se referian a eso. En realidad el colgao era un hombre, que se bamboleaba entre los árboles, mecido por el peso de la muerte. Un columpio abandonado que sigue moviéndose por inercia, en eso pensé, que era un columpio con el que nadie jugaba. Mucho después conoci la vieja historia de la hija del rey lcaro, que se mató a horcándose de pura tristeza cuando su padre murió. Los sủbditos decidieron dejar alli la soga que habla usado, pendiendo de la misma rama que ella había elegido. Con el tiempo los niños empezaron a perderle el miedo dejando que la muerte se convirtiera en un juguete amable, el columpio, que nos deja subir y bajar, poner a prueba nuestro miedo al vacio. Esa es la hermosa leyenda que comunica la vida y la muerte, la infancia y el horror.

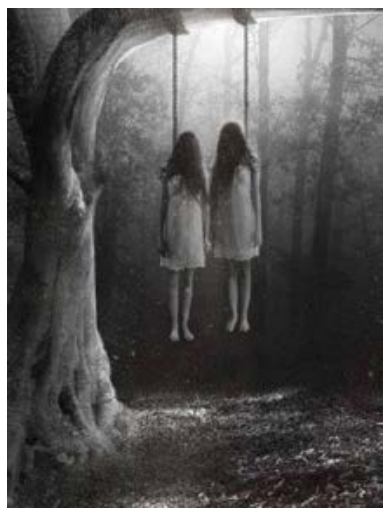

Fuente: Patricia Esteban Erlés, 8 de julio de 2019 Facebook, [imagen adjunta, s. d.], https:// bit.ly/2Xhd4FL

En este microrrelato hipermedial, como su maestra Shirley Jackson, olfatea la trágica historia que brota del secreto del columpio y alza un mundo inquietante; la trama declina cualquier interpretación mimética asociada al motivo del columpio como juguete infantil y lo transforma en una imagen especular y metafórica de los miedos, de la sospecha y de la muerte; tampoco los principios constitutivos de la imagen fotográfica se vinculan a la representación de juego infantil sino a la sostenida voluntad polisémica de la pieza narrativa. La tensión narrativa que proyectan el microrrelato y la fotografía refleja bien "la universalidad estética del texto artístico, tanto en la fisonomía constitutiva de su estructura como en la de los procesos poiético y aisthético -creativo y perceptivo- por los que ese texto se convierte en experiencia" (García Berrio, 1994, p. 633). Nuevamente, la metáfora de la muerte, en su doble vertiente verbal y plástica, invita a la reflexión. Como es habitual en el imaginario de la escritora, lo monstruoso y lo tétrico se aloja en los juegos de la infancia (el columpio, las muñecas), motivos recurrentes a partir de los cuales salda cuentas con las carencias de la niñez y con los lastres que la acompañan. Son variadas las estrategias narrativas que confluyen en ambos lenguajes, como la serialidad, la elipsis, la 
transgresión del nivel ontológico del componente lúdico; y de ambos lenguajes se sirve Esteban Erlés en este imaginario que oscila entre lo íntimo y lo épico, lo local y lo universal, la muerte y el horror del vacío. De la simbiosis semiótica y del juego fronterizo que acaece dentro y fuera del discurso textual-narrativo resurge la subversión de los códigos de la realidad (Sánchez, 2015).

En los universos narrativos de Patricia Esteban Erlés la palabra y la imagen no son mundos aislados sino estrechamente conectados entre sí, como percibimos en este microrrelato:

\title{
Imagen 9
}

Tu cuerpo contaba una historia...

\begin{abstract}
Tu cuerpo contaba una historia, la más triste de cuantas he leído. No sé por qué cada noche insistía en retirar la sábana, cuando dormías, para volver a ella, qué hacía que me doliera todo lo que no he visto ni sé de ti. Tu cuerpo empezaba como todos los cuentos, en un "érase una vez", pero terminaba en un desolador "ya nunca más". No te despertabas ni sabías que leerte era para mí una aventura amarga, porque toda tu piel contaba el olvido, describía el páramo que yo nunca he sabido dejar de amar y el incendio que lo había destruido. Tu cuerpo echaba de menos cada llama, se retorcía inquieto en la ausencia del fuego, se moría, allí, desnudo, en el centro mismo de mi cama, por quien había salido huyendo en cuanto el aire comenzó a oler a sauces y ciervos quemados.
\end{abstract}

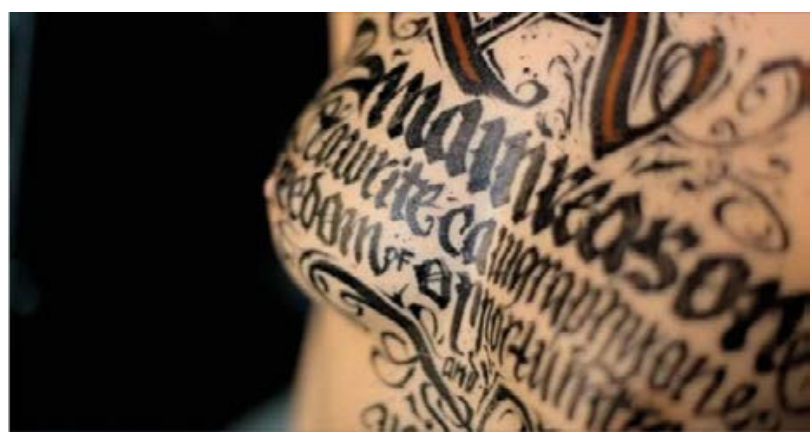

Fuente: Patricia Esteban Erlés, 15 de julio de 2019, Facebook, [imagen adjunta, s. d.], https://bit.ly/307gRHw

La lectura aislada de esta breve pieza narrativa de gran fuerza visual sumerge al lector en la intuición metafórica de lo que ha sido una vida encadenada, que carga y arrastra sobre sí las heridas del pasado. Estamos ante un microrrelato catártico, en el que la voz narradora capta con fuerza expresiva y eficacia visual la belleza del 
horror, plasma el drama que oculta el cuerpo de la persona amada y deja constancia del mal que la ha destruido.

Por su parte, la imagen fotográfica graba a fuego el tatuaje de un mensaje sobre unos pechos de mujer. Si el tatuaje es en sí mismo un cuerpo introducido en un orden simbólico (Thévoz, 1984, p. 18) y una imagen texto-visual que puede reflejar el ethos de una cultura o de una colectividad (Krutak, 2007, p. 229), en esta ocasión se presenta como una escritura textual verbal e icónica dotada de una gran carga semiótica y capacidad simbólica, pues nos sumerge en la historia de una persona que ha decidido transformar su cuerpo para convertirlo en un objeto manipulable y metamorfoseado y para hacer del mismo una construcción personal (Le Breton, 2002, p. 7). Más allá de enfatizar la pertenencia a un grupo, el tatuaje fotografiado es una marca significante de individuación biográfica, con el que una mujer toma registro de una historia vivida, que parece enmascarar una ausencia; más allá de subrayar su autonomía y el control de su existencia, expresa la incomprensión y el sinsentido a través de las fisuras y quiebras de la leyenda imperceptible.

Esteban Erlés comprende que la fotografía condensa un gran poder narrativo y sorprende con esta provocadora propuesta literaria, que no puede ser interpretada en el marco del realismo mimético. Sobresale el alejamiento deliberado de la monosemia comunicativa que aparentemente evoca la imagen. La fotografía tiene un claro efecto desautomatizador en el lectoespectador que es invitado a traspasar la referencialidad del objeto visual y a liberar la polisemia que se deriva de la evocación imaginaria que custodia el tatuaje, abriendo algunas de las posibilidades significativas que esta encierra. Este proceso se desencadena en varias fases; en primer lugar, la imagen fotográfica invita a ensanchar y potenciar la colaboración ficcional del escritor y, tras la constitución estructural del microrrelato hipermedial, es el lector quien ha de acotar las sugerencias que custodia el proceso creativo.

El espacio textual del microrrelato hipermedial simbiótico amplifica las posibilidades semánticas de la imagen sin vulnerar los principios comunicativos del lenguaje estético y artístico que operan tanto en el componente verbal como visual; a pesar de gozar de autonomía textual, semántica y simbólica, texto e imagen entablan una relación de complementariedad en torno a las sombras oscuras 
y a las manchas que crecen en el alma humana; no se nos presentan como un espacio caótico ni sin reglas sintáctico-semánticas de constitución estructural interna sino como una unidad semánticoimaginaria que aloja un universo simbólico, que no es ajeno a la orientación antropológica del ser humano.

\section{Conclusión}

Los microrrelatos hipermediales de Patricia Esteban Erlés muestran, como hemos ido viendo, un ámbito de productividad artística perturbadora que ensancha la experiencia literaria a la estético-visual, con la consiguiente mezcla de placer físico, estético e intelectual. No sorprende que sea así si tenemos en cuenta el amor de la escritora por la obra de fotógrafos consagrados (el ucraniano Arthur "Weegee" Fellig, el húngaro Brassaï, el danés Jan Persson, la estadounidense Sally Mann, la argentina Sara Facio, la libanesa Lara Zankoul, etcétera) que, como la gran Diane Arbus, narran de manera punzante los mundos sórdidos de los espacios domésticos y las grandes urbes, la hermosura y lo deforme, la violencia y la intimidad o la muerte y la ternura a un mismo tiempo. Su obra narrativa, como la de la fotógrafa estadounidense, invita a la introspección de lo humano y al encuentro con aspectos de la sociedad que quizá uno no se atreve a mirar. Ambas permiten ver, con sus juegos de perspectivas y desde la ironía y el distanciamiento, algunos rasgos configuradores de la condición posmoderna: en palabras de Sass (2005), la desarticulación del mundo, la perturbación del yo, el otro lado de la realidad y las sombras que acechan lo humano o la crisis del sentido I

\section{Referencias}

Abello Verano, A. (2019). Cartografías de lo sobrenatural. Imaginería de terror en la narrativa breve de Patricia Esteban Erlés. Dicenda. Estudios de lengua y literatura españolas, 37, 31-49. https:/doi.org/10.5209/ dice.64993

Abril, G. (2012). Tres dimensiones del texto y de la cultura visual. ICRevista científica de Información y Comunicación, 9, 15-35. https://bit. $1 y / 3 h x X z B 3$ 
Albaladejo, T. (2016). Teoría de la Literatura y Estética. Laocoonte: Revista de Estética y Teoría de las Artes, (3), 49-58. https://doi.org/10.7203/ laocoonte.3.3.9357

Andres-Suárez, I. (2008). El microrrelato español: Una estética de la elipsis. Menoscuarto.

Andres-Suárez, I. (2012). Antología del microrrelato español (1906-2011): El cuarto género narrativo. Cátedra.

Arbus, D. (1966-1967). Identical Twins, Roselle, N.J. [archivo fotográfico]. The J. Paul Getty Museum. https://bit.ly/3k7emx1

Arias Urrutia, Á. (2018). Alebrijes virtuales: nuevas voces de la minificción mexicana en la red. En A. Calvo Revilla (Ed.), Elogio de lo mínimo. Estudios sobre microrrelato y minificción (pp. 139-186). Iberoamericana/ Vervuert.

Arias Urrutia, Á., Calvo Revilla, A. y Hernández Mirón, J. L. (2009). El microrrelato como reclamo. La persuasión retórica de la imagen y la palabra. En S. Montesa (Ed.), Narrativas de la posmodernidad. Del cuento al microrrelato (pp. 529-552). AEDILE.

Arnheim, R. (1998). El pensamiento visual. Paidós.

Barthes, R. (1989). Cámara lúcida: Nota sobre la fotografía (J. Sala-Sanahuja, Trad.). Paidós.

Bou, E. (2001). Pintura en el aire (Arte y literatura en la modernidad). Pre-textos.

Brunel, P., y Chevrel, Y. (Eds.) (1989). Précis de littérature comparée. Presses Universitaires de France.

Bustamante Valbuena, L. (2016). La contaminación como recurso creativo en el microrrelato. En E. Álvarez Ramos y M. Martínez Deyros (Eds.), Historias mínimas: Estudios teóricos y aplicaciones didácticas del microrrelato (pp. 133-150). Cátedra Miguel Delibes. http://uvadoc.uva. es/handle/10324/23514

Bustamante Valbuena, L. (2017). Del relato mínimo a la narración aumentada: algunos ejemplos en el microrrelato español actual. Microtextualidades. Revista Internacional de microrrelato y minificción, (1), 26-43. https://bit.ly/2WLJYy8

Calvino, I. (1998). Seis propuestas para el próximo milenio. Siruela. 
Calvo Revilla, A. (2012). Delimitación genérica del microrrelato: microtextualidad y micronarratividad. En A. Calvo Revilla y J. de Navascués (Eds.), Las fronteras del microrrelato. Teoría y crítica del microrrelato español e hispanoamericano (pp. 15-36). Iberoamericana/ Vervuert.

Calvo Revilla, A. (2016). Cartografía del microrrelato en red. Nuevos circuitos literarios (2000-2015). En E. Álvarez Ramos y M. Martínez Deyros (Eds.), Historias mínimas: Estudios teóricos y aplicaciones didácticas del microrrelato (pp. 55-94). Cátedra Miguel Delibes. http:// uvadoc.uva.es/handle/10324/23514

Calvo Revilla, A. (2017). Microrrelato en red: intermedialidad y redes de interacción en la cultura textovisual. La obra de Juan Yanes y Araceli Esteves. En L. Bocanegra y A. García López (Eds.), Con la Red / En la Red: Creación, investigación y comunicación cultural y artística en la era de Internet (pp. 78-106). Universidad de Granada-Downhill Publishing.

Calvo Revilla, A. (2018a). Institucionalización y canonización del microrrelato. Las revistas como espacio de creación, circulación y difusión del género. En Elogio de lo mínimo: Estudios sobre microrrelato y minificción en el siglo XXI (pp. 43-92). Iberoamericana/Vervuert.

Calvo Revilla, A. (2018b). Espectacularización barroca del ingenio en la Tuiteratura. Microrrelato, mutaciones y otros textos marginales en Twitter. En M. Jacob y A. R. Posada (Eds.), Narrativas mutantes: Anomalía viral en los genes de la ficción (pp. 222-239). Ars Docendi.

Calvo Revilla, A. (2019a). Microrrelato hipermedial: simbiosis e hibridación semiótica y proyección significativa. En T. Gómez Trueba (Ed.), Página y Pantalla: Interferencias microficcionales (pp. 149-167). Ediciones Trea.

Calvo Revilla, A. (2019b). Microrrelatos, microformas literarias y microtextualidades en la red hipermedial. En Epifanías de la brevedad: Microformas literarias y artísticas en la red (pp. 9-16). Visor.

Calvo Revilla, A. (2019c). Lo siniestro y la subversión de lo fantástico en Casa de muñecas, de Patricia Esteban Erlés. En M. Martínez Deyros y C. Morán (Eds.), Pasado, presente y futuro del microrrelato hispánico (pp. 113-132). Peter Lang.

Carrillo Martín, N. (2018). Blogs y microrrelato: de lo desechable a lo 
imprescindible. En A. Calvo Revilla (Ed.), Elogio de lo mínimo. Estudios sobre microrrelato y minificción en el siglo xxI (pp. 125-138). Iberoamericana/Vervuert.

Carrión, J. (2011). Teleshakespeare. Errata Naturae.

Chevrel, Y. (2009). La littérature comparée. Presses Universitaires de France.

De Micheli, M. (2001). Las vanguardias artísticas del siglo xx. Alianza Editorial.

De la Varga Llamazares, R. (2015). Mujeres que matan: dimensiones del monstruo en Patricia Esteban Erlés. En N. Álvarez Méndez y A. Abello Verano (Eds.), Espejismos de la realidad. Percepciones de lo insólito en la literatura española (siglos XIX-XxI) (pp. 233-242). Universidad de León.

Derrida, J. (1968). La Différance [Conferencia pronunciada en la Sociedad Francesa de Filosofía, el 27 de enero de 1968]. En J. Derrida (1998), Márgenes de la filosofía (C. González Martín, Trad.). Cátedra.

Díez Cobo, R. M. (2018). Ecos góticos en el microrrelato contemporáneo en español: una travesía en/tre orillas atlánticas. Microtextualidades. Revista Internacional de microrrelato y minificción, (5), 45-66. https:// bit.ly/3hG4b0n

Escandell Montiel, D. (2018). El anclaje textovisual de los memes en las micronarraciones de la red. En A. Calvo Revilla (Ed.), Elogio de lo mínimo: Estudios sobre microrrelato y minificción en el siglo XXI (pp. 221241). Iberoamericana/Vervuert.

Esteban Erlés, P. (2008a). Abierto para fantoches. Diputación Provincial de Zaragoza.

Esteban Erlés, P. (2008b). Manderley en venta. Tropo Editores y Universidad de Zaragoza.

Esteban Erlés, P. (2010). Azul ruso. Páginas de Espuma.

Esteban Erlés, P. (2012). Casa de muñecas. Páginas de Espuma.

Esteban Erlés, P. (2017, agosto 8). Shirley Jackson, Silvina Ocampo, Fleur Jaeggy, Cristina Fernández Cubas, Lydia Davis, Patricia Highsmith, Mariana Enríquez... [Actualización de estado]. [Imagen adjunta: "Woman Carrying a Child in Central Park, N.Y.C., 1956", de Diane Arbus], https://bit.ly/3gvOFnD 
Esteban Erlés, P. (2017, septiembre 25). Eran tres hermanos, tenían tres tamaños distintos y la misma cara triste, como las matrioscas [Actualización de estado]. [Imagen adjunta: fotografía de Diane Arbus], fecha de acceso: 26 de abril de 2019, https://bit.ly/3k2H0is

Esteban Erlés, P. (2018, diciembre 25). En esta ciudad pasa de todo. Por ejemplo, ya no reparten el verbo vivir en la puerta de algunos cines como antes. [Actualización de estado]. [Imagen adjunta: Twins Paper Bags de Nicolás Ferrando, a partir de las Twins de Diane Arbus], Facebook. Fecha de acceso: 26 de abril de 2019, https://bit.ly/2PfDaEI

Esteban Erlés, P. (2018a). Entrevista a Patricia Esteban Erlés, de Gonzalo Jiménez Tapia. Microtextualidades. Revista Internacional de microrrelato y minificción, (3), 212-216. https://bit.ly/39jmTYA

Esteban Erlés, P. (2018b). Entrevista a Patricia Esteban Erlés. En I. Touton (Ed.), Intrusas: 20 entrevistas a mujeres escritoras (pp. 273-278). Institución Fernando el Católico.

Esteban Erlés, P. (2018c). Las madres negras. Galaxia Gutenberg.

Esteban Erlés, P. (2019). Fondo de armario. Contraseña.

Esteban Erlés, P. (2019, julio 7). Tu muerte era muy pequeña, cabía en una toalla nueva, que aún olía a nueva. [Actualización de estado]. [Imagen adjunta, s. d.]. Facebook. https://bit.ly/2PILFON

Esteban Erlés, P. (2019, julio 8). Me acuerdo de cuando confundimos la muerte con un columpio. [Actualización de estado]. [Imagen adjunta, s. d.]. Facebook. https://bit.ly/2Xhd4FL

Esteban Erlés, P. (2019, julio 15). Tu cuerpo contaba una historia, la más triste de cuantas he leído. [Actualización de estado]. [Imagen adjunta, s. d.]. Facebook. https://bit.ly/307gRHw

Esteban Erlés, P. (2019, julio 18). Te peinaré siempre que tú me lo pidas, le decía la gemela fea a la gemela guapa, asumiendo su papel... [Actualización de estado]. [Imagen adjunta, s. d.]. Facebook. https://bit.ly/3gb8cJJ

Esteban Erlés, P. (2020, mayo 31). Esta imagen de Diane Arbus siempre me sobrecoge. Una mujer lleva un niño en brazos y camina por Central Park... [Actualización de estado]. [Imagen adjunta: "Woman Carrying a Child in Central Park, N.Y.C., 1956", de Diane Arbus]. Facebook. https://bit.ly/3fY8vrj 
Gandelman, C. (1991). Reading pictures, viewing texts. Indiana University Press.

García Berrio, A. (1994). Teoría de la Literatura (La construcción del significado poético), 2. ed., revisada y ampliada. Cátedra.

García Berrio, A. y Hernández Fernández, T. (1986). Semiótica del discurso y texto plástico del esquema textual y la construcción imaginaria. Estudios de lingüística: ELUA, (3), 47-86. http://hdl.handle. net $/ 10045 / 6620$

Giraldo, E. (2015). Los límites artísticos en los ensayos sobre arte y estética de Baldomero Sanín Cano. Aistheis. Revista Chilena de Investigaciones Estéticas, (58), 145-171. http://dx.doi.org/10.4067/S071871812015000200008

Guillén, C. (2005). Entre lo uno y lo diverso. Introducción a la Literatura Comparada (Ayer y hoy). Tusquets.

Hernández, D. (2018). Enredaderas de la minificción: algunos microrrelatistas en España con mayor presencia en Internet. En A. Calvo Revilla (Ed.), Elogio de lo mínimo: Estudios sobre microrrelato y minificción en el siglo xxI (pp. 113-124). Iberoamericana/Vervuert.

Higgins, D. (1966). Intermedia. Something Else Newsletter, 1 (1), 1-6.

Holtzman, S. R. (1994). Digital Mantras. The languages of abstract and virtual worlds. MIT Press.

Kristeva, J. (1969). Bakhtine, le mot, le dialogue et le roman. En Semiotikè. Recherches pour une sémanalyse (pp. 143-173). Seuil.

Krutak, L. (2007). The tattoing art of tribal women. Bennett \& Bloom/ Desert Hearts.

Le Breton, D. (2002). Signes d'identité: tatouages, piercings et autres marques corporelles. Métailiè.

Louvel, L. (2002). Texte/image: Images à lire, textes à voir. Presses Universitaires.

Lucie-Smith, E. (2000). Artes visuales en el siglo xx. Könemann.

Merleau-Ponty, M. (1970). Lo visible y lo invisible. Seix Barral.

Mitchell, W. J. T. (1994). Picture Theory: Essays on Verbal and Visual Representation, Chicago University Press. 
Model, L. (2010). Lisette Model. Fundación Mapfre.

Monegal, A. (1996). La imagen fugaz: el rastro de la visualidad en la escritura. Moenia, 2, 309-326. http://hdl.handle.net/10347/5956

Monegal, A. (Ed.) (2000). Literatura y pintura. Arco Libros.

Monegal, A. (2016). Sombras de lo real. La relación entre las artes en el diálogo entre la pintura de Antonio López y el documental de Víctor Erice. Rassegna Iberistica, 39(106), 307-324. https://bit.ly/2OR3rJm

Mora, V. L. (2012). El lectoespectador. Seix Barral.

Navarro Romero, R. M. (2014). Literatura breve en la red: el microrrelato como género transmediático. Tonos digital. Revista de estudios filológicos, (27), 1-12. https://bit.ly/2ZQBl7b

Noguerol, F. (2008). Minificción e imagen: cuando la descripción gana la partida. En I. Andres-Suárez y A. Rivas (Eds.), La era de la brevedad: El microrrelato hispánico (pp. 183-206). Menoscuarto.

Noguerol, F. (2010). Micro-relato y posmodernidad: textos nuevos para un final del milenio. En D. Roas (Ed.), Poéticas del microrrelato (pp. 77100). Arco Libros.

Ortel, P. (2002). La Littérature à lère de la photograhie: Enquête sur une révolution invisible. Jacqueline Chambon.

Pageaux, D.-H. (1994). La littérature générale et comparée. Armand Colin.

Perkowska, M. (2013). Pliegues visuales: narrativa y fotografía en la novela latinoamericana contemporánea. Iberoamericana/Vervuert.

Rajewski, I. (2005). Intermediality, Intertextuality, and Remediation: A Literary Perspective on Intermediality. Intermédialités/Intermedialities, (6), 43-64. https://doi.org/10.7202/1005505ar

Riffaterre, M. (1994). Lillusion d'ekphrasis. En G. Mathieu-Castellani (Ed.), La Pensée de l'image: Signification et figuration dans le texte et dans la peinture (pp. 211-229). Vincennes: PUV.

Roas, D. (2010). Sobre la esquiva naturaleza del microrrelato. En Poéticas del microrrelato (pp. 9-42). Arco Libros.

Ródenas de Moya, D. (2008). El microrrelato en la estética de la brevedad del arte nuevo. En I. Andres-Suárez y A. Rivas (Ed.), La era de la brevedad: El microrrelato hispánico (pp. 25-46). Menoscuarto. 
Sánchez Villadangos, N. (2015). Lo fantástico frente a lo real y lo grotesco en los cuentos de Patricia Esteban Erlés. Tropelías. Revista de Teoría de la Literatura y Literatura Comparada, (23), 473-486. https://doi. org/10.26754/ojs_tropelias/tropelias.201523769

Sarabia, R. (2003). Interarte vanguardista y algunas cuestiones teóricocríticas a considerar. Revista Canadiense de Estudios Hispánicos, 28(1), 45-69. https://bit.ly/3hxZaXh

Sass, L. (2005). "Hyped on clarity": Diane Arbus and the postmodern condition. Raritan, 25(1), 1-37. https://bit.ly/2OObV3P

Sontag, S. (1973). Sobre la fotografía. Edhasa.

Thévoz M. (1984). The painted body: the illusions of reality. Rizzoli.

Villanueva, D. (1994). Curso de teoría de la literatura. Taurus.

Wagner, P. (1996). Introductions: Ekphrasis, Iconotexts, and Intermedialitythe State(s) of the Art(s). En Icons-Texts-Iconotexts. Essays on Ekphrasis and Intermedialty (pp. 33-36). Walter de Gruyter.

Walker, J. A. y Chaplin, S. (2002). Una introducción a la cultura visual. Octaedro-EUB.

Walzel, O. (1917). Wechselseitige Erhellung der Künste. Ein Beitrag zur Würdigung kunstgeschichtlicher Begriffe. Reuther \& Richard.

Weisstein, U. (1975). Introducción a la Literatura Comparada. Planeta.

Wellek, R. y Warren, A. (1979). Teoría literaria, 4.ㄹ ed. Gredos. 